\title{
O BELO (IN)VISÍVEL DA CRIANÇA ALBINA NA LITERATURA INFANTOJUVENIL
}

\author{
THE BEAUTIFUL (IN)VISIBLE OF THE ALBINA
} CHILD IN CHILDREN'S LITERATURE

\author{
Solange de Sousa Araújo*
}

\begin{abstract}
Resumo
O texto traz uma reflexão sobre o significado do "belo" contido nos livros de literatura infantil inclusiva: Sabrina: a menina albina, da autora Celina Bezerra; Pedrinho: o menino albino de Patrícia Prado e $A$ menina sem cor, de Fernanda Emediato. Para isso, utilizamos algumas provocações referentes à beleza, contidas no livro: O fantástico mistério da Feiurinha, de Pedro Bandeira. Temos como objetivo apresentar aos novos pesquisadores, possibilidades alternativas para se olhar a beleza, referente às crianças albinas. Em um mundo marcado pela diversidade, não existe uma beleza, senão várias. As pessoas albinas são branquinhas, de olhos claros, mas não estão no contexto do midiático, por essa razão óbvia, são discriminadas e postas à margem. Metodologicamente, fazemos análise qualitativa do conteúdo dos livros para falarmos sobre aspectos subjetivos e fenômenos sociais relacionados às pessoas albinas e a forma como vivem em um mundo marcado pelo preconceito. Este trabalho representa o desejo de inserir os temas do albinismo nas discussões acadêmicas, contribuindo para ampliar o conhecimento pela causa albina, na educação, na saúde e despertar o interesse em saber quem são as pessoas albinas, para assim amenizar ou extinguir o preconceito com esse "povo branquinho".
\end{abstract}

Palavras-chave: diferença; beleza; literatura infantojuvenil inclusiva; pessoas albinas.

\begin{abstract}
The text is a reflection on the meaning of the beauty contained in the books of inclusive children's literature: Sabrina: a menina albina, by the author Celina Bezerra; Pedrinho: o menino albino of Patrícia Prado and A menina sem cor, by Fernanda Emediato. For this, we use some taunts related to beauty, contained in the book: $\mathrm{O}$ fantástico mistério de Feiurinha, by Pedro Bandeira. We aim to present to new researchers alternative possibilities of looking at beauty in reference to albino children. In a world marked by diversity, there is no single beauty, but several. Albino people are white with light-colored eyes, but in the context of the media are discriminated against and marginalized. Methodologically, we conduct a qualitative analysis of the content of books in order to reflect upon subjective aspects and social phenomena related to albino people and the way they live in a world marked by prejudice. This work represents the desire to insert the themes of albinism into academic discussions, contributing to an extension of knowledge of the albino cause, in education, in health and to arouse interest in knowing who albino people are, in order to soften or extinguish prejudice against these "white people".
\end{abstract}

Keywords: difference; beauty; inclusive children's literature; albino people.

\footnotetext{
* Graduada em Letras (português) pela Universidade Vale do Acaraú/Brasil. Graduada em Letras (espanhol) pela Universidade Estadual da Paraíba/Brasil. E-mail: solange.sousa.araujo@hotmail.com.
} 


\section{Introdução}

Iniciamos o artigo com a seguinte indagação: O que é belo?

De acordo com o dicionário Aurélio (FERREIRA, 2008), belo significa: (1) aquilo que tem forma perfeita e proporções harmoniosas; (2) algo que é agradável aos sentidos; ou ainda, (3) o que é elevado, sublime, entre outros.

Neste artigo, refletiremos sobre a beleza ${ }^{1}$, tentando mostrar que, na nossa sociedade, ela se refere à harmonia, pois tudo que se diz belo se associa ao que é harmonioso. Mais do que isso, ser belo é ser bom, porque, na nossa cultura, estética está intimamente relacionada à ética. Mas a beleza é relativa, e não necessita de coisas inacreditáveis para acontecer; ela simplesmente é fato, é algo real contido em cada pessoa, portanto faz parte da personalidade individual. $\mathrm{O}$ que propomos neste artigo vem nos trazer reflexões que poderão nos levar a pensar sobre o quanto já fomos machucados ou quanto já machucamos psicologicamente outras pessoas - com julgamentos irrelevantes - em nome da beleza, do belo.

Tentamos demostrar que com a alteridade existente em cada um de nós pode significar: em primeiro lugar, respeitar o próximo como gostaríamos de ser respeitado, e em segundo, a tratar meu "irmão" como eu gostaria de ser tratado, e com ela passaremos a ampliar uma sociedade justa, fraterna, humana, equilibrada, democrática e tolerante, na qual expressar-se, desde que haja harmonia e respeitem a alteridade, visando assim um olhar de acato.

Se olharmos algo ou alguém de uma forma menos rígida, sem deixar que fatores externos influenciem nossas decisões - o que não é fácil, pois compartilhamos os valores, símbolos, regras e demais elementos da nossa cultura — , o significado da palavra "belo" se tornaria realmente sublime, elevado e harmonioso. Porém, na maioria das vezes, extraímos nosso conceito do "belo" das diversas mídias que impõem como os seres humanos devem se vestir e agir, e é a partir disso que se produzem e se reproduzem vários tipos de racismos, preconceitos, discriminações e fobias.

Vale destacar que é a na infância onde toda nossa fase adulta se construirá, nesse propósito, cabe às pessoas tornarem cada momento vivido mais leve, com clareza das

\footnotetext{
${ }^{1}$ Uma busca rápida na internet usando a palavra "beleza" como descritor vai nos levar ao encontro de muitas definições, mas todas enfatizando, direta ou indiretamente, a questão do harmonioso, equilibrado, agradável, simétrico etc.
} 
condições que cada criança irá enfrentar no futuro, porém com argumentos esclarecedores, utilizando palavras adequadas à cada faixa etária.

Do ponto de vista metodológico, a reflexão que se faz aqui é fruto de estudos qualitativos que têm o foco nos fenômenos sociais que marcam o cotidiano das pessoas albinas. A análise do discurso, quase em forma de resenha, que faremos de três obras de literatura infantil (inclusiva), cujas personagens se constroem a partir de questões da cor, com destaque para as pessoas com albinismo, leva-nos a falar sobre as qualidades pessoais delas, as quais vão além do coitadismo ou do discurso de vitimização. É a partir da reflexão sobre o "belo" - assunto caro à filosofia desde a Antiguidade —, o qual nem sempre se sabe evidenciar, que se construiu este artigo.

O corpus da análise engloba três obras principais e um quarto livro para suporte comparativo. São eles: Sabrina, a menina albina, da autora Celina Bezerra, publicado em 2019. Sabrina é uma menina albina, irmãzinha de Lucas, que a amava muito. O enredo do livro se desenvolve no seio de uma família em que apenas Sabrina é albina. Destaca-se o esforço dos pais para explicarem ao menino o porquê de Sabrina ser branquinha para ele, assim, entender e explicar aos menos esclarecidos.

O segundo livro: Pedrinho, o menino albino, de autoria de Patrícia Prado, publicado em 2011, apresenta um menino albino muito querido por todos, até que um dia se deparou com um garoto implicante, que, muito insistentemente, queria saber o motivo de Pedrinho ser tão branco. Diante da incapacidade de explicar para seu interlocutor o porquê da sua cor, ele foi para casa chorando. Lá chegando, perguntou a sua mãe a razão de ele ser branquinho. Ela, muito sábia, respondeu-lhe dizendo que ele era branquinho porque era albino.

O terceiro livro é A menina sem cor, escrito por Fernanda Emediato em 2019. O livro narra a vida de uma menina albina, filha de um casal de cor preta e que se achava diferente por causa da sua cor.

O quarto livro, do qual extrairemos algumas indagações pertinentes para se pensar a situação das personagens albinas dos outros livros, é O fantástico mistério da Feiurinha, de autoria de Pedro Bandeira, publicado em 2001. Relata a história de uma menina discriminada por ser diferente. Ela, apesar de ter uma beleza admirável, achava que não estava nos chamados padrões de beleza. $\mathrm{O}$ enredo contém fatos que nos conduzem a reflexões referentes ao amor, medo, alegria, ciúme e rejeição. Também nos leva a refletir sobre como se fortalece a mediocridade alheia frente àquilo que é diferente, desconhecido. O dito "normal" — aquele 
que se encontra em conformidade com os padrões considerados de "normalidade" dentro da sociedade - pouco se mostra interessado em conhecer ou ter empatia pelas pessoas consideradas destoantes.

Essa intertextualidade do livro: $O$ fantástico mistério da Feiurinha com os demais livros vem fortalecer a relevância de tratarmos bem as demais pessoas, independentemente de suas condições físicas ou psicológicas, e ajuda-nos a buscar os conhecimentos necessários para sairmos da ignorância contida em nossas mentes muitas vezes desprovidas de conhecimentos básicos sobre como devemos nos comportar perante o "diferente", o "outro".

Os livros foram selecionados por estarem inseridos no gênero literário infantojuvenil de vertente inclusiva. Entendemos essa vertente como um esforço que tem se propagado como forma de desconstruir modelos educacionais e midiáticos que reforçam a discriminação e o preconceito contra as minorias ou pessoas com deficiência. Vale lembrar que nenhum/a dos/as autores/as dos livros é pessoa com albinismo.

\section{Apresentação das obras}

Sabrina, a menina albina. Sabrina é uma menina que desde o ventre foi muito desejada por seus pais e pelo irmãozinho Lucas. Quando nasceu, a notícia de que era uma menina branquinha, rapidamente se espalhou. Muitas visitas ela recebeu, especialmente por curiosidade devido aos comentários sobre sua aparência. Lucas, porém, ama a sua irmã como ela é, e a compara com um raio de sol. Certa vez, seu pai explicou que Sabrina era semelhante à sua bisavó, que também era albina, pois não tinha melanina no corpo, portanto era uma herança genética. Por não ter a tal melanina, certamente a menina não poderia tomar sol, caso isso acontecesse, iria prejudicar o corpinho da menina. A partir daí, Lucas passou a cuidar amorosamente da pele da irmãzinha, sempre aplicando sobre ela o protetor solar, lembrandolhe de não esquecer dos óculos escuros para proteção dos seus olhinhos. Sabrina se tornou conhecida por toda a redondeza.

Pedrinho, o menino albino. Notamos que ele é filho de pais negros, alegre e esperto e que mora na zona rural, no outro lado do rio, gosta muito de brincar com as coisas do campo e com os amigos da escola. Às vezes, dizem que ele é diferente. Certa vez, um "amiguinho" conhecido por Digão the perguntou o porquê de ele ser tão "brancão"? Triste, Pedrinho foi para casa chorando, chegando lá, a sua mãe perguntou o motivo do choro; ele explicou o fato. 
A mãe, com todo carinho, explicou-lhe que ele é um menino albino e que por sermos "diferentes" não nos tornamos melhores ou piores que os outros, somos apenas diferentes. Depois dessa conversa, Pedrinho se tranquilizou e aceitou que é Pedrinho, o menino albino.

Em A menina sem cor, Olívia é uma menina albina com a pele claríssima, olhos lilases, cabelos, sobrancelhas e cílios brancos. Tornou-se amiga de Micaela, uma filha adotiva de pele preta e que não gosta da sua cor, por conta disso elogia muito a cor de Olívia. Ambas têm cores diferentes e com isso Olívia explica a razão pela qual sua pele é tão branca, relata que se trata de uma anomalia genética e que por falta de pigmentação na pele, pelos, cabelos e olhos não pode se expor ao sol. Para a proteção da pele, é necessário o uso contínuo e regular de protetor solar, e nos dias mais quentes, tem que evitar sair, além disso, a maioria das pessoas albinas possuem problemas de baixa visão e alguns podem até perdê-la. Aprendizado recebido de sua mãe, Olívia e Micaela chegaram à conclusão de que essa questão da cor é uma irrelevância e que na verdade o bom da vida é serem amadas.

Nessa perspectiva, faz-se relevante mencionar que há um apelo para que a sociedade discuta os direitos igualitários entre as pessoas e, sobretudo, em relação às crianças albinas. Conforme mencionam Ero e colaboradoras (2021):

De acordo com a CRPD [Convenção das Pessoas com Deficiência], os Estados devem adotar medidas que atendam aos melhores interesses da criança, a fim de garantir que crianças com albinismo possam desfrutar de todos os seus direitos em igualdade de condições com as demais. (ERO et al., 2021, p. 95).

Em se tratando de direitos, antes de qualquer coisa, o ser humano necessita ser respeitado, independentemente de sua condição social, sexualidade, cor, religião entre outros. A criança precisa ser respeitada, para que desde a sua infância, se torne um adulto que saiba respeitar os outros.

O fantástico mistério da Feiurinha apresenta uma proposta inovadora dos contos de fadas tradicionais, pois traz uma espécie de "continuação" dos outros, a partir do "era uma vez", e concluindo com o conhecido: "foram felizes para sempre”. A história ocorreu há muitos anos. Ela é mais uma personagem que se casou com um príncipe encantado. Ainda na infância, foi roubada dos seus pais por três bruxas, Ruim, Malvada e Piorainda, que cometeram o delito por terem inveja da beleza daquela menina, que passou a morar em uma simples choupana com três bruxas e a sobrinha delas, onde sofreu abusos psicológicos. As malvadas queriam convencê-la de que era feia e elas eram lindas, como se Feiurinha estivesse 
fora dos "padrões" de beleza. Ela foi considerada desaparecida, contudo, as princesas do lugar decidiram fazer uma reunião para tentar solucionar o problema do tal desaparecimento da Feiurinha. Foi quando um escritor descobriu o motivo de não a encontrarem. O fato é que a sua história não estava escrita em livros, só passada de geração a geração. Então, apareceu Jerusa que narrou a história para os presentes na reunião.

Seu nome, Feiurinha, foi dado pelas bruxas malvadas, pois, tinham uma sobrinha muito feia, a qual puseram o nome Belezinha, elas tinham inveja da beleza da Feiurinha, e queriam roubar o "belo" existente na menina para elas. No sítio onde viviam, havia um bode, que quando Feiurinha tinha oportunidade, conversava com ele, e, certa vez, quando se aproximava dos seus quinze anos, as bruxas saíram e deram muitas tarefas para a menina cumprir, então ela, triste, foi desabafar com o bode, mas ele se transformou em um belo príncipe, quebrando o feitiço que as bruxas nele colocaram. Ele elogiou a beleza da Feiurinha, e falou que as bruxas eram muito más e que a convenceram que ela era feia, porém, ela tinha uma beleza admirável. O príncipe saiu, mas prometeu que iria voltar em breve para se casar com Feiurinha e serem felizes para sempre. Quando as bruxas retornaram, perceberam que o bode não se encontrava, imediatamente acharam que Feiurinha havia quebrado o feitiço, então fizeram-na contar o que havia acontecido, com isso, colocaram uma pele de urso nela, transformando-a em mais uma bruxa.

Não demorou muito e o príncipe voltou. Ao chegar, as bruxas quiseram confundi-lo, dizendo-lhe que Feiurinha havia se transformado em uma bruxa. Mas a nova bruxa intercedeu pelas bruxas malvadas frente às ameaças do príncipe. Ele logo percebeu a doçura que havia no seu coração, então passou a espada de prata no manto de urso e quebrou o feitiço. Casouse com ela que depois encontrou seus verdadeiros pais, os quais já estavam velhinhos, e foram "felizes para sempre".

Com esses textos, iremos refletir um pouco sobre como o nosso egocentrismo pode destruir a alteridade, a qualidade do outro pela qual o ser é considerado diferente. Não é raro vermos pessoas maltratando outras com palavras, gestos ou atitudes grosseiras, simplesmente pelo fato de elas serem "incomuns", "diferentes".

O que esses livros têm em comum? Todos eles citam crianças com belezas incomuns que sofreram preconceitos por serem "diferentes". As crianças enfrentaram momentos difíceis, foram estigmatizadas, quase sempre, por pessoas próximas, do convívio cotidiano. Porém há famílias estruturadas, nas quais os filhos são educados para viverem seguros em 
relação aos preconceitos que possam surgir. Feiurinha representa a exceção: uma menina que viveu longe de quem a amava, mas que soube lidar, com supremacia, com os problemas existentes.

Os livros citados pertencem à literatura infantojuvenil inclusiva, e são de extrema relevância para esta pesquisa, pois vêm agregar conhecimentos sobre a condição albina e sua beleza que, por ser rara, chama a atenção. O tema amplia o campo de pesquisa para os futuros pesquisadores da condição albina.

\section{Propósito}

Sabe-se que ser uma pessoa "diferente" não é fácil, pois, constantemente, ela é vítima de olhares, os quais, nem sempre são de admiração, mas de estranhamento, curiosidade, críticas, sem falar nas palavras de preconceito, humilhações e xingamentos. Essas são ocorrências comuns para as pessoas albinas, e a pior fase é a infância, momento crítico da construção pessoal, cujos efeitos perdurarão por toda a vida. Roberto Bíscaro, albino importante no meio, nos diz: “Às vezes ainda me xingam, ou fazem comentário maldosos sobre minha aparência. Agora servem como justificativa para provar que a causa albina tem fundamento e árduo trabalho pela frente, para diminuir o preconceito (BÍSCARO, 2012, p. 249).

A intenção deste trabalho é causar uma provocação em relação ao "belo" da pessoa dita "não normal", ou seja, um belo atípico que, muitas vezes, é rejeitado por não se enquadrar no padrão de "normalidade". A sociedade já se acostumou com o que a mídia dita como padrão de beleza: olhos claros, cabelos loiros e lisos, corpo estrutural, seios fartos (no caso das mulheres).

Sabemos que o albinismo é

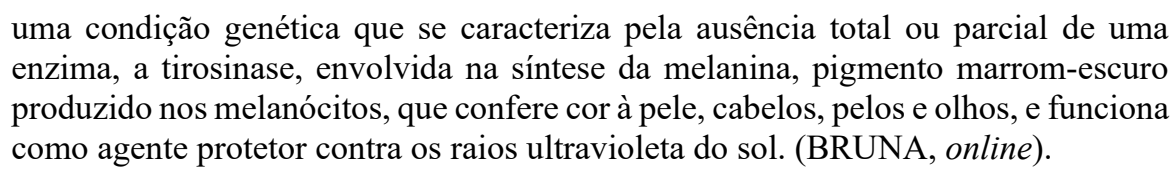

De acordo com a língua portuguesa, pode-se explicar a origem do nome albinismo.

Conforme Melo: 


\begin{abstract}
A palavra albinismo vem do termo em latim Albus, que significa branco, sendo também sinônimo de acromo, acromia e acromatose, que significa deficiência ou ausência de pigmentação nos tecidos. Essa anomalia é rara, sua natureza é hereditária e tem caráter recessivo, ou seja, as ocorrências de albinismo passam de geração a geração, podendo ficar longo período sem se manifestar. Sua causa é uma mutação genética que resulta em pouca ou nenhuma produção de melanina, produzida pelas células chamadas de melanócitos. (MELO, 2017, p. 18).
\end{abstract}

Condição rara, da qual ainda há muito o que aprender, gerando a necessidade de ter mais visibilidade, sobretudo nas políticas públicas, na mídia, cultura, educação e até na medicina. Sem falar nas questões étnico/raciais, cor, estigma, gênero e geração.

Por falar em geração, ao explicar um pouco da realidade das crianças albinas, e que estão representadas nos livros em pauta, quando nasce uma criança albina, geralmente causa indagações de desconfiança por parte de algumas pessoas, conforme aponta Bezerra (2019, p. 13) ao relatar o nascimento de Sabrina: “'Olha como ela é loirinha', exclamou dona Laurinha. 'Ela parece filha de alemão', disse espantado o tio João. 'Essa menina não tem cor!' Sussurrava dona Leonor. Cochichavam num entra e sai: não se parece nada com o pai." Tais comparações maldosas causam dor, sofrimento, e reforçam o estigma de ser uma criança albina, além de culpabilizar a mulher por ter tido um filho albino o que, muitas vezes, afeta a estrutura familiar.

O contexto do livro é semelhante à vida real de uma criança albina, como, por exemplo, Roberto Rillo Bíscaro descreve: "Desde o nascimento tenho chamado a atenção. Sou como um pop star. Aonde quer que vá, sou olhado, encarado. Pessoas literalmente param na rua para me ver passar, como se fossem paparazzi seguindo um cantor pop. Só falta a fortuna". (BÍSCARO, 2012, p. 70).

Além dos olhares de estranhamento, há questionamentos e perguntas frequentes feitas aos pais das crianças albinas: "É seu filho biológico?” "Tem certeza de que o pai da sua criança é esse que está criando?" "Por que ele ou ela nasceu dessa cor?" "Na família tinha algum antepassado branquinho assim?” São fatos que afetam a estima e a estrutura familiar.

Danos provocados por palavras impensáveis podem causar tristezas e prejuízos irreversíveis. Vejamos como Patrícia Prado traduziu essa questão para a literatura:

Um dia quando voltava da escola, Pedrinho encontrou Digão, o menino implicante e bobão. Digão logo perguntou: - Ô Pedrinho. Porque você é tão brancão? Sem saber o que responder, Pedrinho começou a chorar... Afinal, ele também não sabia por que era tão diferente... Pedrinho foi para casa voando, como um pássaro assustado. (PRADO, 2011, p. 3-4). 
O preconceito pode "afetar a autoestima" de um ser que já vem fragilizado por consequências anteriores de rejeições, de não aceitação, pois ser considerado "diferente" por conta da sua aparência, não é fácil.

Ainda sobre o preconceito, na obra $A$ menina sem cor, Mimi, passeando em um domingo no parque, ficou olhando toda aquela variedade de cor de pele, e foi sentindo um desejo enorme de ter outra cor qualquer, menos a sua (EMEDIATO, 2020, p. 9). Por ignorância e arrogância pessoal, esquecemos inúmeras vezes que da mesma forma que queremos os nossos direitos respeitados, devemos respeitar e conhecer os direitos do próximo, conforme mencionado na Declaração Universal dos Direitos Humanos: “Todos são iguais perante a lei e, sem distinção, têm direito a igual proteção da lei. Todos têm direito a proteção igual contra qualquer discriminação que viole a presente Declaração e contra qualquer incitamento a tal discriminação." (ORGANIZAÇÃO DAS NAÇÕES UNIDAS, 1948, online).

Não é fácil se libertar do preconceito, até é possível amenizá-lo em algumas situações, mas as leis são os mecanismos mais eficientes para garantir que o cidadão seja defendido contra atos que o abalam física ou psicologicamente.

No livro $O$ fantástico mistério da Feiurinha, há momentos terríveis de violência psicológicas, nos quais a menina indefesa não sabia se defender. Esses danos podem acarretar problemas para a vida inteira. Conforme Pedro Bandeira menciona em sua obra literária:

Ai como sou feia! Ai como sou infeliz! [...] Veja minha imagem refletida na água do lago. Veja como eu sou feia [...]. Como sou infeliz [...]. Belezinha e minhas madrastas até que têm razão de brigar comigo. Para elas, deve ser duro morar com um ser tão feio, tão horroroso como eu! (BANDEIRA, 2001, p. 50-51).

Conforme mencionado acima, a menina se sente "terrivelmente feia", devido às agressões ouvidas; sofreu a vida inteira, sendo estigmatizada constantemente por sua aparência. Mesmo sendo admiravelmente linda, não acreditava na sua condição de ser bela.

De um modo bem peculiar, os livros em foco servem para ampliar o conhecimento das pessoas que veem uma pessoa albina como "diferente", e não sabem lidar com elas, com isso, eles servirão para diminuir a curiosidade existente, além de trazerem conhecimento sobre a relativização do "belo" contidos nas histórias. 
As obras em foco relatam fatos que destacam outro tipo de beleza, o qual raramente é percebido, pois a mídia e a moda ditam as regras, e estabelecem um determinado conceito do que é "belo" para que sigamos e acreditemos nele como um "belo" absoluto.

Outra razão pela qual resolvemos elaborar este artigo, é que há poucos meios que falam sobre o tema albinismo no âmbito educacional, algo também percebido por outros autores, a exemplo de Melo:

\begin{abstract}
No Brasil, os albinos vivem uma espécie de invisibilidade (entende-se que este termo é utilizado quando se refere aos indivíduos socialmente invisíveis, seja pela diferença, exclusão, estigma, preconceito, aqueles que vivem à margem da sociedade). Oficialmente não existe dados estatísticos sobre esta população. Os poucos dados existentes, vêm do campo da medicina, restringindo o conhecimento e/ou debate entre os dermatologistas, acentuando os aspectos nosológicos da questão. Nas universidades também não se tem encontrado grandes estudos, exceto alguns artigos no estado da Bahia e no Maranhão, justamente os locais nos quais encontramos o maior número de albinos no Brasil (MELO, 2017, p. 35).
\end{abstract}

Por tais motivos, desejamos que o conhecimento, por meio de pesquisa e estudos, se expanda, a fim de se buscar respeito e visibilidade para essa população, que ainda é vista pelos olhos do preconceito, e se tornam invisíveis quando se trata de direitos, das políticas públicas, das diversas áreas da literatura, do mercado de trabalho, da assistência social etc.

Do mesmo modo queremos frisar mais um detalhe sobre o aspecto familiar: o apoio da família a uma criança albina é essencial, pois é dentro dela que se aprende a conviver com os demais grupos, tais como: amigos, escola, trabalho e afins. O papel da família é instruir e acolher a criança, e em se tratando de pessoas com albinismo, oferecer suporte de proteção contra os vários preconceitos e discriminação que ela enfrentará. Assim, é necessário que os pais saibam e lhe ensinem os cuidados especiais que elas precisam ter com sua saúde: em relação à visão, à proteção da sua pele etc. Além disso, ensinar-lhe a ser desbravadora, forte e corajosa como aconteceu ao menino Roberto Bíscaro, conforme suas palavras: "Era uma vez, um menino branquinho, de cabelos de algodão e olhos d'água. Fraco sim, mas disposto a tudo. Era eu e minha criancice, resolvi matar o sol. Inimigo imponente, o Sr. Sol, ardia em mim, castigava e me fazia sofrer. Era ele ou eu." (BÍSCARO, 2012, p. 15).

Nesse contexto de educar com responsabilidade, os pais do menino ainda aproveitaram para dar exemplo de responsabilidade escolar, cumprindo as tarefas, junto com conselhos de economia: "Entra pra dentro que não é hora de brincar, vem fazer a tarefa [...]. E não mexe mais com o sol! Será possível? A gente não tem dinheiro pra comprar outro”. (BÍSCARO, 2012, p 16). 
Atualmente, a responsabilidade de criar e educar os filhos também está direcionada aos avós, tio/tias, professores/as, cuidadoras escolares, e com isso, os pais estão se "livrando" (por questões ou sociais, econômicas e políticas etc.) dessa obrigação. Além disso, deve-se considerar a ausência do Estado de garantir os direitos e deveres para com essas crianças. No futuro, elas poderão não estar preparadas para lidar com os problemas e dificuldades que encontrarão pelo caminho. Sabemos que a presença física e emocional dos pais é de suma importância para toda criança, e principalmente para as crianças que necessitam de cuidados especiais, como as albinas.

Em resumo, respeito é o que a maioria das pessoas necessita, muitas vezes, mais do que outros sentimentos. O respeito, a empatia, o esclarecimento são virtudes que controlam nossas palavras e gestos. Que não saiam das nossas bocas palavras de repúdio, desprezo, insultos, ofensas contra o outro simplesmente por ele/ela ser diferente.

\section{Considerações finais}

As obras mencionadas trazem provocações referentes ao albinismo. Seus títulos já deixam explícitas as condições das crianças-personagens: albino/a; "sem cor"; sem melanina, o que aguça a curiosidade dos leitores sobre tema tão pouco apresentado pela literatura de uma forma geral.

Nas obras, é relatada a vida das crianças albinas, as quais têm apoio familiar; seus pais esclarecem a condição genética e o histórico familiar que eles carregam, para que elas não se tornem "inocentes" quanto às suas condições, e quando forem vítimas de chacota, tenham conhecimento e sabedoria para reagir positivamente. Percebe-se também que nos livros há uma abordagem sobre o preconceito, notório entre as crianças albinas, e quase sempre vindo por meio de "amiguinhos", que de modo inocente ou por maldade, machucam com palavras os colegas albinos. Um detalhe importante é a inteligência dos "albininhos", pois todos eles sabem sair do local de vítima, porque desde cedo tiveram o apoio de suas famílias, foram bem esclarecidos sobre a condição de ser "diferente".

É importante também que os profissionais da educação tenham conhecimento sobre o tema, para que eles ajudem as crianças no contexto ensino/aprendizagem, assim como no âmbito socioeducativo, o qual abrange o convívio escolar com os amiguinhos. É válido, 
inclusive, que os profissionais da saúde conheçam melhor sobre o albinismo, pois, assim, irão ampliar seus conceitos e ajudar a lapidar os diagnósticos.

$\mathrm{Na}$ vida real nem sempre é fácil entender a situação das pessoas albinas como nos contos de fadas: a princesa sofre com as malvadezas que a cercam, porém encontra seu príncipe encantado, casam-se, e vivem felizes para sempre sem nenhum tipo de sofrimento após o matrimônio, o que não acontece na dura realidade vivida por uma pessoa com albinismo.

Os contos de fadas vêm ampliar nossos conceitos sobre a beleza. O fantástico mundo da Feiurinha, por exemplo, leva-nos a pensar sobre o "belo" e seus questionamentos: todo conto de fadas começa por, "era uma vez" e terminam com "e ficaram felizes para sempre? A pessoa só é feliz se encontrar um homem, como no caso das princesas? Será que existe felicidade eterna? As bruxas são mesmo más?

Enfim, concluindo, os livros analisados aqui, relatam que todos nós temos problemas, porém com ajuda e orientação, eles se tornam amenos, além de abranger nossa mente para a questão do que colocam nela em relação ao belo relativo e a beleza que a mídia constrói. No caso das pessoas albinas, o fenótipo é algo marcante e peculiar, fugindo dos padrões de beleza atual. Talvez em alguns países nórdicos, a pessoa albina passe despercebida, porém, no Brasil, isso não acontece. Aqui, pessoas com albinismo precisam elaborar estratégias de sobrevivência e adaptação para conviver com o albinismo e com as pessoas não albinas.

Em suma, desejamos que este material venha enriquecer o conhecimento em relação aos cuidados necessários para que as crianças albinas consigam conviver com sua condição e sejam aceitas como são. Com isso esperamos somar às escritas futuras, e que sirva como tema de interesse nas áreas: acadêmica, educacional, pedagógica, literária etc.

\section{Referências}

BANDEIRA, Pedro. O fantástico mistério da Feiurinha. São Paulo: Editora FTD, 2001. v. 5.

BEZERRA, Celina. Sabrina: a menina albina. Curitiba: Editora Inverso, 2019.

BÍSCARO, Roberto Rillo. Escolhi ser albino. São Carlos: EdUFSCar, 2012.

BRUNA, Maria H. V. Albinismo. Site Dráuzio Varella. Disponível em: https://drauziovarella.uol.com.br/doencas-e-sintomas/albinismo/. Acesso em: 26 nov. 2021. (Sem indicação de data de postagem). 
ORGANIZAÇÃO DAS NAÇÕES UNIDAS. Declaração universal dos direitos humanos. 1948. Disponível em: http://www.ohchr.org/EN/UDHR/Documents/UDHR_Translations/por.pdf. Acesso em: 20 jun. 2016.

EMEDIATO, Fernanda. A menina sem cor. São Paulo: Editora Troia, 2020.

ERO, I. et al. Pessoas com albinismo no mundo: uma perspectiva de direitos humanos. [S. 1.; s. n.], 2021. Disponível em: Albinism_Worldwide_Report2021_PT.pdf(ohchr.org). Acesso em: 27 jul. 2021.

FERREIRA, Aurélio Buarque de Hollanda. Minidicionário Aurélio. 4. ed. Rio de Janeiro: Editora Nova Fronteira. 2008.

MELO, José Adailton Vieira Aragão. Guerreiros do sol e da lua. República da Moldávia: Novas Edições Acadêmicas, 2017.

PRADO, Patrícia. Pedrinho: o menino albino. Belo Horizonte: Editora Nandyala, 2011.

Recebido em: 28/08/2021.

Aceito em: 18/10/2021. 